\title{
Mine Burial Experiments at the Martha's Vineyard Coastal Observatory
}

\author{
Peter Traykovski, Michael D. Richardson, Larry A. Mayer, and James D. Irish, Member, IEEE
}

\begin{abstract}
Several experiments to measure postimpact burial of seafloor mines by scour and fill have been conducted near the Woods Hole Oceanographic Institution's Martha's Vineyard Coastal Observatory (MVCO, Edgartown, MA). The sedimentary environment at MVCO consists of a series of rippled scour depressions (RSDs), which are large scale bedforms with alternating areas of coarse and fine sand. This allows simultaneous mine burial experiments in both coarse and fine sand under almost identical hydrodynamic forcing conditions. Two preliminary sets of mine scour burial experiments were conducted during winters 2001-2002 in fine sand and 2002-2003 in coarse sand with a single optically instrumented mine in the field of view of a rotary sidescan sonar. From October 2003 to April of 2004, ten instrumented mines were deployed along with several sonar systems to image mine behavior and to characterize bedform and oceanographic processes. In fine sand, the sonar imagery of the mines revealed that large scour pits form around the mines during energetic wave events. Mines fell into their own scour pits, aligned with the dominant wave crests and became level with the ambient seafloor after several energetic wave events. In quiescent periods, after the energetic wave events, the scour pits episodically infilled with mud. After several scour and infilling events, the scour pits were completely filled and a layer of fine sand covered both the mines and the scour pits, leaving no visible evidence of the mines. In the coarse sand, mines were observed to bury until the exposed height above the ripple crests was approximately the same as the large wave orbital ripple height (wavelengths of 50-125 cm and heights of 10-20 cm). A hypothesis for the physical mechanism responsible for this partial burial in the presence of large bedforms is that the mines bury until they present roughly the same hydrodynamic roughness as the orbital-scale bedforms present in coarse sand.
\end{abstract}

Index Terms-Acoustic imaging, mine burial, scour, sediments.

\section{INTRODUCTION}

$\mathbf{T}$ 10 improve our ability to predict burial of mines on the seafloor, the U.S. Office of Naval Research (ONR, Arlington, VA) sponsored a series of mine burial experiments at

Manuscript received April 13, 2005; revised September 9, 2005; accepted October 24, 2005. This work was supported in part by the U.S. Office of Naval Research under Grants N00014-01-10564 and N0004-01-1-0847, by the Department of Defense Presidential Early Career Award, and by the U.S. Naval Research Laboratory (NRL) Core funding under Program 061115N. This is the Woods Hole Oceanographic Institution (WHOI) contribution number 11349 and the NRL publication number NRL/JA/7430-05-3.

Guest Editor: R. H. Wilkens.

P. Traykovski and J. D. Irish are with the Applied Ocean Physics and Engineering Department, Woods Hole Oceanographic Institution, Woods Hole, MA 02543 USA (e-mail: ptraykovski@whoi.edu).

M. D. Richardson is with the Marine Geosciences Division, the U.S. Naval Research Laboratory, Stennis Space Center, MS 39529 USA (e-mail: mike. richardson@nrlssc.navy.mil).

L. A. Mayer is with the Center for Coastal and Ocean Mapping/National Oceanic and Atmospheric Administration (NOAA) Joint Hydrographic Center, University of New Hampshire, Durham, NH 03824 USA (e-mail: lmayer@ ccom.unh.edu).

Digital Object Identifier 10.1109/JOE.2007.890956 the Martha's Vineyard Coastal Observatory (MVCO, Edgartown, MA) [1]. One of the major problems in the experimental validation of mine burial models is the difficulty of continuous measurement of the behavior of the mine. In past experiments, qualitative observations by divers were limited to 1-2 times a day and then, only during good weather conditions. Burial is an episodic behavior often triggered by energetic wave conditions or strong tidal currents. Divers rarely observe either mine movements or the actual burial process, but instead observe the beginning and ending conditions. Laboratory experiments have difficulties related to scale, especially concerning sediment grain size, surface gravity waveheight and period, bedform size, and mine shape, size, and weight [2], [3]. There is also a large body of literature related to scour around structures on the seafloor [4], but the mine burial problem is somewhat different from scour around a stationary object in that the mine is free to fall into its own scour pit. To overcome some of these difficulties, instrumented mines were combined with high-frequency imaging sonars mounted on poles near the mines to fully characterize this time-dependent burial process (Fig. 1) [1]. Ultimately, the models designed to predict mine burial require a process-based description of the events leading to mine burial. The observations conducted during this study were designed to elucidate the sediment transport processes leading to mine burial by observing the seafloor topography near the mine, including bedforms and scour. These experiments investigated subsequent burial on time scales of days to months after initial impact as opposed to impact burial which can occur on initial impact with the seafloor if the mine is dropped on to soft sediments [5].

Two sets of mine scour burial experiments were conducted during winters 2001-2002 and 2002-2003 (henceforth referred to as years 1 and 2), with a single optically instrumented mine and a rotary sidescan sonar to monitor mine behavior during energetic wave events and to test wave-induced scour burial models (Fig. 1) [6]. These experiments were preparatory for a larger ONR experiment conducted during winter 2003-2004 [7]. Several site characterization cruises were conducted with high-resolution-focused multibeam bathymetry (Reson 8125, [8]), sidescan sonar mapping, a chirp sonar seismic survey, surface grain-size analysis at a large number of stations, and 1-3-m vibracores at a smaller number of stations [9]. During the major experimental program, 16 mines were deployed from October 2003 to April 2004 (year 3), along with several bottom-mounted systems to image mine behavior and to characterize bedform and oceanographic processes. 


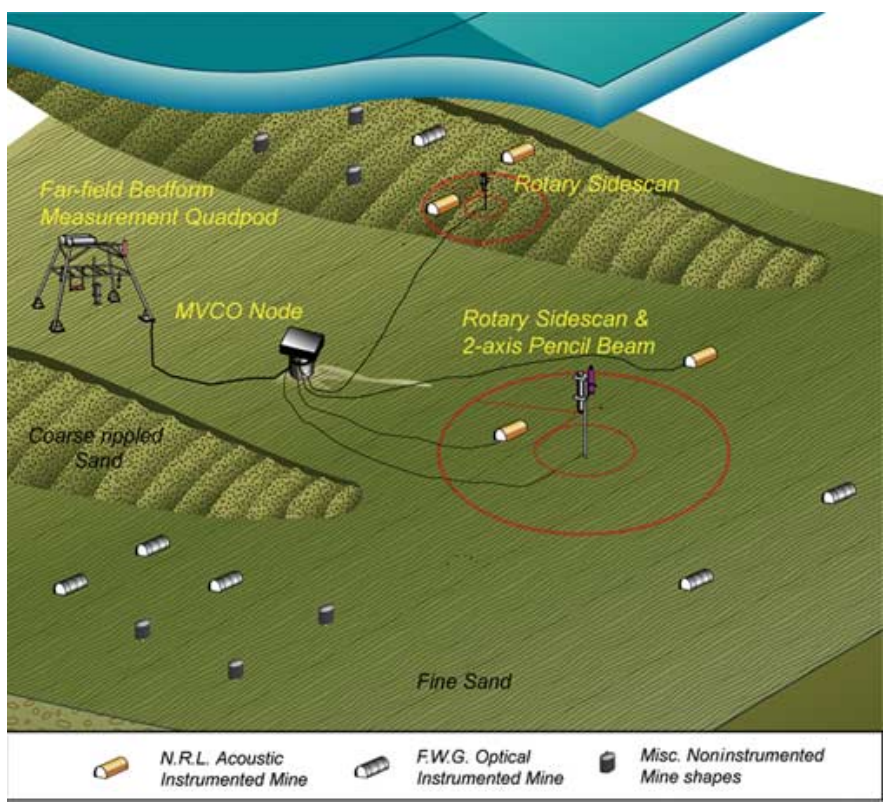

Fig. 1. Schematic of the MVCO node area showing the fine sand near the node and coarse rippled sand approximately $100 \mathrm{~m}$ from the node. The layout of acoustic and optical instrumented mines relative to the imaging sonars is also shown.

\section{ENVIRONMENTAL CONDITIONS}

\section{A. Oceanographic Conditions}

The oceanographic forcing for sediment transport and scour burial at MVCO is dominated by waves from southerly directions [Fig. 2(d)]. Waves from the north are blocked by Martha's Vineyard, and waves from the northeast and east are blocked by the shallow (2-3 m depth) Wasque shoals located to the east of the study site. Waveheights are typically the largest from October to March, with occasional large wave events in the late summer from passing tropical storms or hurricanes (Fig. 3). The largest wave events observed over the three measurement years had significant waveheights of 3-4 m and occurred approximately $5-10$ times per year and typically lasted $2-4$ days, as measured by an acoustic Doppler current profiler (ADCP) located on the MVCO node in 12-m water depth. Wave events with significant waveheights between 2 and $3 \mathrm{~m}$ occurred between 10 and 20 times per year. Peak wave periods during energetic wave conditions range from 8 to $13 \mathrm{~s}$. The near-bed wave orbital velocities generated by the largest wave events at the MVCO site in 11-12-m water depth reach root-mean-square (rms) values of $50-70 \mathrm{~cm} / \mathrm{s}$. Bottom currents are typically tidal with peak velocities of $10-20 \mathrm{~cm} / \mathrm{s}$ at an elevation of $1 \mathrm{~m}$ above the bed. Combined wind and tidal forced generated bottom currents can reach $30-40 \mathrm{~cm} / \mathrm{s}$; however, not all large wave events have associated strong mean currents. Wave orbital velocities dominated both sediment resuspension at these water depths and scour around the mines since waves produce a larger shear stress than mean currents with similar velocities. This is due to the thinner wave boundary layer (approximately $5-10 \mathrm{~cm}$ thick) relative to the thicker mean current boundary layer (approximately $1-5 \mathrm{~m}$ thick) [10].

\section{B. Seabed Characteristics}

1) Large Scale Bedforms: The seafloor at MVCO consists of a series of features known as rippled scour depressions (RSDs) or sorted bedforms [Figs. 1 and 2(a)] [9], [11], [13]. These are shore-perpendicular swaths of coarse sand $(250-1000 \mu \mathrm{m}$, Fig. 4) with along-shore widths ranging from tens to hundreds of meters and cross-shore lengths of one to several kilometers [Fig. 2(a)] that are bathymetrically offset (typically deeper) from the surrounding seafloor. The regions between the coarse sand are covered by a layer of fine sand (90-250 $\mu \mathrm{m}$, Fig. 4) ranging from 15 to $50 \mathrm{~cm}$ in thickness. Based on seismic profiles, grab samples and vibracores coarse sands underlie the fine sands, and a gravelly layer is often present at the vertical transition from fine to coarse sand [9]. The gravel layer is also present approximately $10-80 \mathrm{~cm}$ below the surface in the coarse-sand zones in some cores. Near the mine burial experiment, the transition from fine to coarse sand is marked bathymetrically by a drop of approximately $20-50 \mathrm{~cm}$. The interiors of the coarse-sand zones are mounded with their shoalest points often reaching the same height as the surrounding fine sands. This bathymetric expression is variable throughout the survey area as the RSDs in eastern portion of the study area deepen toward the east, and the RSDs in western portion of the study area deepen to the west [Fig. 2(a)] [9].

2) Small Scale Bedforms: The coarse sand supports wave orbital-scale bedforms with wavelengths $\left(\lambda_{r}\right)$ of $50-125 \mathrm{~cm}$ and heights $\left(\eta_{r}\right)$ of 5-20 cm [Fig. 2(b)] [11], [12]. As the name implies, these ripples have wavelengths and waveheights that scale with wave orbital diameter. These bedforms have been observed by rotary sidescan sonars to migrate in response to surface gravity wave velocity skewness. This generally results in onshore migration at rates of approximately one wavelength per day. During moderate-energy conditions, the wave orbital ripples are very long crested features [11]. However, during the most energetic conditions, with coarse-sand Shields numbers [14] of 0.2-0.3, the coarse-sand bedforms become irregular and migrate at rates of 2-3 wavelengths per day. Shields numbers were calculated based on wave velocities alone, using a Swart [15] wave friction factor. Wave-current interactions were not included in the stress calculations as mean currents add only $10 \%-15 \%$ to the total stress during energetic wave events at this location.

In the fine sand, during low-energy wave events, small anorbital wave ripples were present Fig. 2(c). These bedforms have wavelengths of approximately $15 \mathrm{~cm}$ roughly consistent with anorbital ripple scaling of $\lambda_{r}=535 d_{50}$, where $d_{50}$ is the median grain diameter [16]. As expected for anorbital scaling, the ripples do not change wavelength in response to varying wave velocities. During large wave events, with fine-sand Shields numbers of 0.5-0.7, these small ripples were washed out. The high-resolution bathymetric surveys also identified medium scale low-relief bedforms in the fine sand similar to those observed by Green and Black [17] [Fig. 5(a) and (c)]. These features have length scales of 3-10 m and heights of $10-15 \mathrm{~cm}$ and have an irregular geometry. The migration or geometric evolution of these features may play an important role in the final complete burial and infilling of scour pits around mines located in fine sand. Based on the observations at 


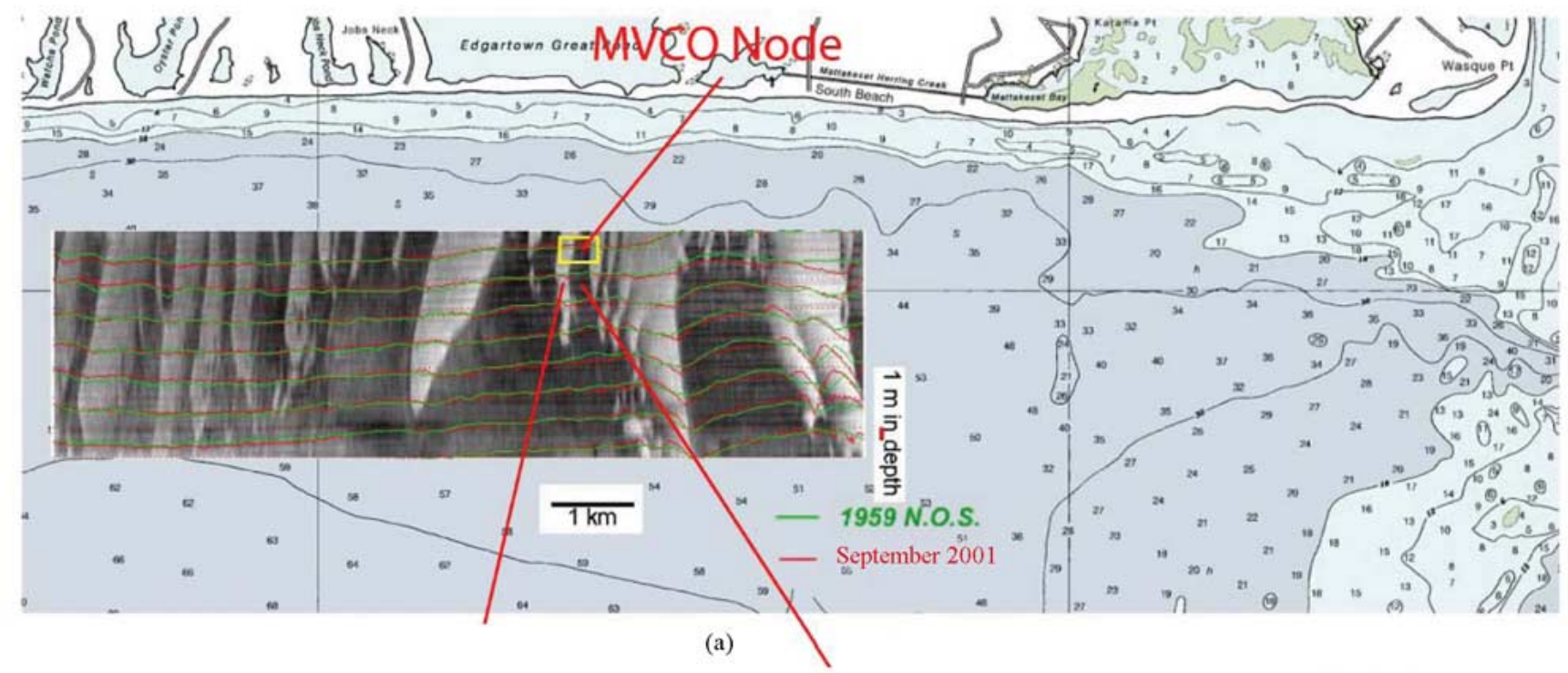



(b)



(c)



(d)

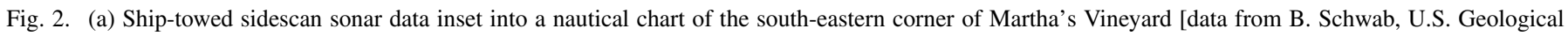

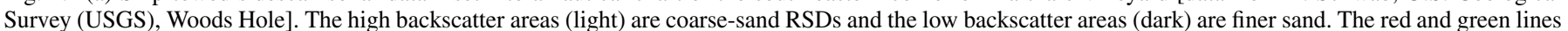

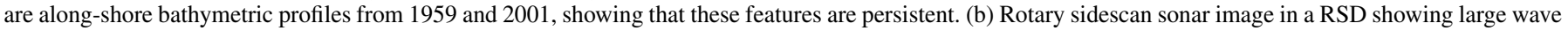

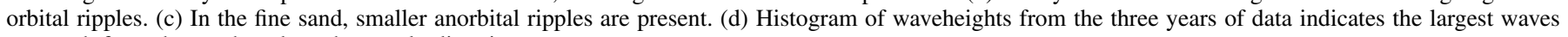
approach from the south and southwesterly directions.

MVCO, it is not known if these medium scale features persist through high-energy wave events, as the slopes associated with these features are too low to be imaged by the rotary fanbeam sonars. However, indirect estimates of bed roughness based on suspended sediment concentrations and near-bed stresses, performed by Green et al. [18], suggest that such features do persist through energetic wave events. At MVCO, the high-resolution multibeam bathymetry surveys show they are transient over seasonal to annual time scales, as they appear in some surveys, but not in others taken several months apart.

\section{METHODS: InSTRUMENTS AND DEPLOYMENTS}

\section{A. Instrumented Mines}

1) Optical Mines: The optical instrumented mine (Fig. 6) is a useful tool for continuous monitoring of the movement of the mine (heading, pitch, and roll) as well as the percentage of the surface area of the mine actually buried [6]. The U.S. Naval Research Laboratory (NRL, Stennis Space Center, MS) design is based on an instrumented mine developed by I. Stender of
Forschungsanstalt der Bundeswehr für Wasserschall-und Geophysik (FWG, Kiel, Germany) [19]. Heading of the mine $\left( \pm 1^{\circ}\right)$ is measured with three solid-state compasses; roll and pitch $\left( \pm 1^{\circ}\right)$ of the mine are measured with a three-axes accelerometer. Burial is measured by three rings of paired optical sensors externally mounted at $15^{\circ}$ intervals around the mine. Transmitting optical sensors are light-emitting diodes (LEDs) and receiving sensors are phototransistors. Burial is measured by sediment blockage between these sensors. Each sensor is assumed to represent an equal area of mine surface, thus the reported percent burial is the percentage of sensors that are blocked. The mine in Fig. 6 is made of aluminum and is $1.5 \mathrm{~m}$ long and $0.47 \mathrm{~m}$ in diameter. The mass of the mine is $619 \mathrm{~kg}$. Thus, producing a mine with density of $2379 \mathrm{~kg} / \mathrm{m}^{3}$ (2.4 times that of water) and a weight in water of $356 \mathrm{~kg}$. During the experiments in years 1 and 2, measurements were made every 2-5 min and transmitted to a computer at the MVCO shore station on Martha's Vineyard, which is connected to the Internet.

2) Acoustic Mines: To overcome some of the problems with the optical mines (e.g., biofouling and enhanced turbulence due 



Fig. 3. Time series of significant waveheight for the three winter seasons during which mines were deployed at MVCO. The dashed line is the seasonal waveheight envelope calculated from a running 95 percentile filter. The gray-shaded regions represent the periods of the mine burial deployments.

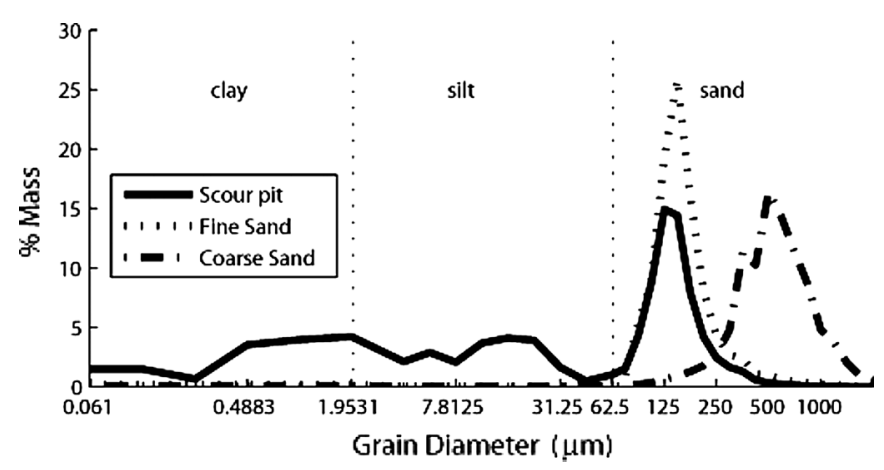

Fig. 4. Grain-size distributions from a sediment samples taken in the scour pit of a buried mine (solid line), in the fine-sand region of an RSD outside the scour pit (dotted line), and in the coarse-sand region of the RSD (dash-dotted line).

to the protruding sensors), Omni Technologies, Inc., Stennis Space Center, MS, and the NRL designed and built four bronze acoustically instrumented mines (AIMs) (Fig. 6) [20]. The geometry of the AIMs are similar to the optical mines with a length of $2.03 \mathrm{~m}$, a diameter of $0.533 \mathrm{~m}$, and a weight in air of approximately $900 \mathrm{~kg}$. This translates to a density of $1984 \mathrm{~kg} / \mathrm{m}^{3}$ and a weight in water of $440 \mathrm{~kg}$ [20]. These instrumented mines had 112 surface-mounted acoustic transducers designed to measure surface burial and the direct path radial distance to the sediment-water interface relative to the mine. These acoustics transducers can be used to measure the geometry of the scour near the mine, but do not allow determination of the full extent of the scour pit or the interactions between bedforms and the scour pit. Similar to the optically instrumented mines, the AIMs had heading, pitch, roll, and several conditionally sampled acceleration sensors. Unique to the newer AIM design was a measurement of pressure fluctuations (six pressure sensors on each mine), which are used to calculate wave statistics and tidal heights. Mean pressure fluctuations can also be used to estimate changes in mine elevation relative to either a fixed pressure sensor located nearby or to mean tidal heights. The MVCO node provided a fixed pressure sensor, thus the difference between pressure from the AIMs and the node could be used to estimate relative changes in mine elevation [21].

\section{B. Sonar Imaging Systems}

1) Rotary Fanbeam Sonars: The basic principles of rotary sidescan sonar operations are well documented elsewhere [22], [24]; thus here, only procedures specific to estimating parameters related to mine burial will be described. In the preliminary experiments, a rotary sidescan sonar made by Kongsberg Simrad, Kongsberg, Norway, with a $2.5-\mathrm{MHz}$ transducer and fixed at 5-m maximum range [22] was used to image an optically instrumented mine. At this frequency, the backscattered acoustic energy was sufficiently attenuated so that the imaged area had an effective radius of approximately $4 \mathrm{~m}$. During year 3 main deployment, a rotary sidescan sonar manufactured by Imagenex, Port Coquitlam, BC, Canada, was also used. This sonar had a transmit frequency of $1.3 \mathrm{MHz}$, and thus, could be set to a range of $10 \mathrm{~m}$ due to the lower acoustic attenuation at this frequency. The rotary sidescan sonars were mounted on 4-m-long poles with the data loggers and approximately $2 \mathrm{~m}$ of pole was water-jetted into the seafloor. The transducers were typically mounted 1.4-1.9 $\mathrm{m}$ above the seafloor, which provided a good compromise between spatial resolution and seafloor area in the main lobe of the beam pattern, given the constraints of imaging a 2-m-long mine, the associated scour pit, and surrounding bedforms. Mounting the sonar higher would result in lower resolution, due to beam spreading, but a larger spatial area imaged, if the acoustic attenuation was not too high. The instrumented mines were usually placed $2-3 \mathrm{~m}$ from the imaging sonars. The sonar backscatter images were used to track the position and orientation of the instrumented mine and to characterize changes in 




(a)

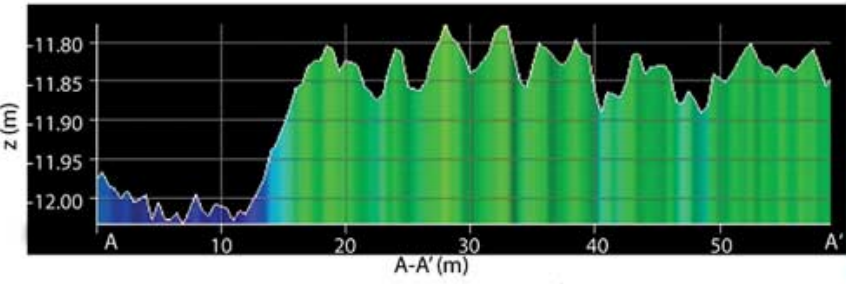

(b)
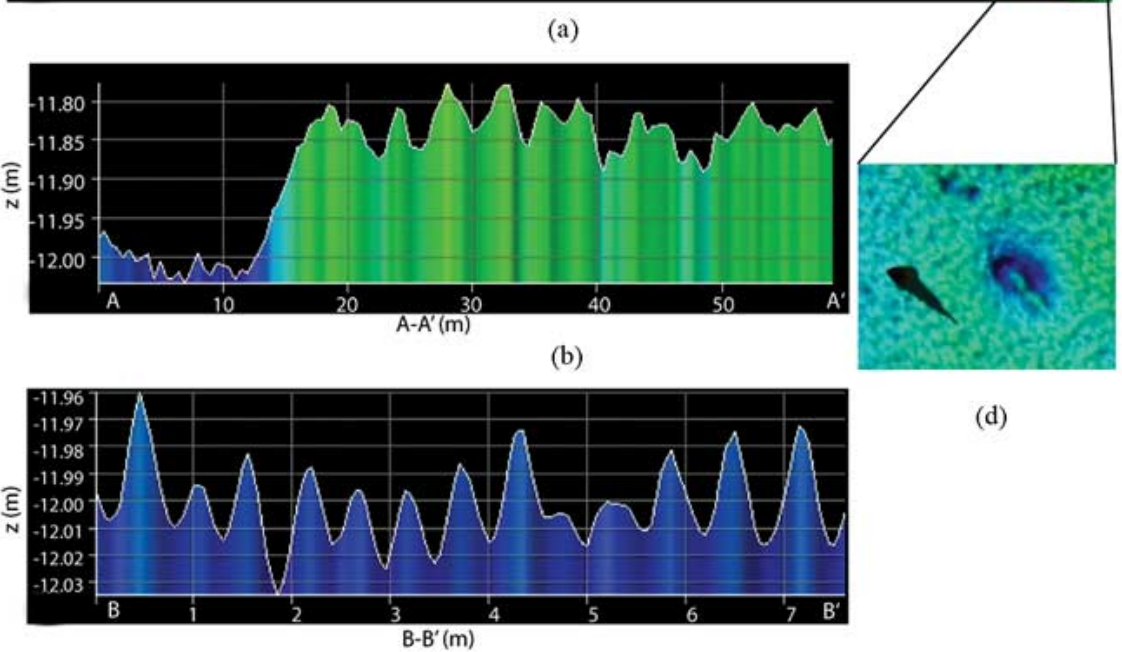

(d)

(c)

Fig. 5. Multibeam bathymetry taken in May 2002 [8]. (a) Two swaths resolving the MVCO node, a transition from coarse (left) to fine sand (right), medium scale low-relief bedforms (right of the transition), and the instrumented mine. (b) Transect from the bathymetry along line A- $\mathrm{A}^{\prime}$ shows the step-like rise in elevation to fine sand associated with RSD morphology and 10-15 cm elevation changes associated with medium scale (3-10 m) bedforms. (c) Multibeam bathymetry also resolves the coarse-sand orbital-scale bedforms $\left(60-\mathrm{cm}\right.$ wavelength and 5-cm height) as shown on transect B-B ${ }^{\prime}$. (d) Optical instrumented mine, its scour pit, and the rotary sidescan sonar mounted on a pole nearby.

seafloor morphology, especially formation and infilling of scour pits, during the mine burial experiment.

To analyze the data from the sonar images in terms of the hydrodynamic forcing parameters, time series of geometric parameters were estimated from the sonar images (Fig. 7). In the rotary sidescan imagery, the presence of an exposed mine is visible primarily through its acoustic shadow (area between blue and red line in Fig. 7). The shadow begins at a location near the top of the mine and ends at the intersection of a ray from the sonar head grazing the top of the mine and intersecting the seafloor [Fig. 8(a) and (b)]. Some acoustic scattering also occurs from the surface of the mine facing the sonar (area between blue and green line in Fig. 7). The height of the mine can be inferred from the length of the acoustic shadow cast by the mine (Fig. 8)

$$
H_{\text {mine }}=\frac{s_{p}}{s_{p}+d_{\text {mine }}} H_{\text {sonar }} .
$$

Here, $s_{p}$ is projected acoustic shadow length, $d_{\text {mine }}$ is the distance from the sonar to the center of the mine, and $H_{\text {sonar }}$ is the height of the sidescan transducer above the seafloor (Fig. 8). The length of the projected acoustic shadow $\left(s_{p}\right)$ was estimated by manually measuring the distance from the centerline of the mine to the shadow at each end ( $s_{1}$ and $s_{2}$ in Fig. 7). These numbers were projected onto the path from the sonar to the mine and averaged to form a single projected shadow length estimate $\left(s_{p}\right.$ in Fig. 7 and Fig. 8). Some error may have been introduced due to difficulty in estimating the position of the centerline of the mine. This projected shadow length can be used to relate the exposed height of the mine relative to the seafloor onto which the shadow is cast [Fig. 8(a) and (b)].

The size of the scour pit can be inferred from the region of low backscatter associated with the scour pit (white hatched area in Fig. 7). This reduced backscatter in the scour pit is either due to the angular dependence of backscattered intensity as the surface of the scout pit faces away from the sonar, an actual acoustic shadow, or the accumulation of relatively fine-grained sediments in the scour pit.

If the scour pit is small relative to the shadow [i.e., at the initial stages of burial, Fig. 8(b)], $H_{\text {mine }}$ reflects the height above the ambient seafloor and a small error exists between an estimate of surface area burial derived from the shadow length and the surface area buried $\left[B_{\text {area }}\right.$ in Fig. $\left.8(\mathrm{~b})\right]$ as measured by the optical sensors on the mine. In this case, changes in $H_{\text {mine }}$ should be consistent with changes in the depth of the mine burial [ $B_{\text {depth }}$ in Fig. 8(a)]. An independent measure of $B_{\text {depth }}$ is also obtained from the pressure difference between the MVCO node and the AIM. Conversely, as the scour pit becomes larger than the shadow length, $H_{\text {mine }}$ in Fig. 8(b) is an estimate of the height of the mine above the local seafloor in the scour pit and an estimate of the surface area buried derived from the shadow length [ $B_{\text {area }}$ in Fig. 8(b)] would be consistent with the actual surface area buried as measured by the optical sensors on the mine. In 




(a)

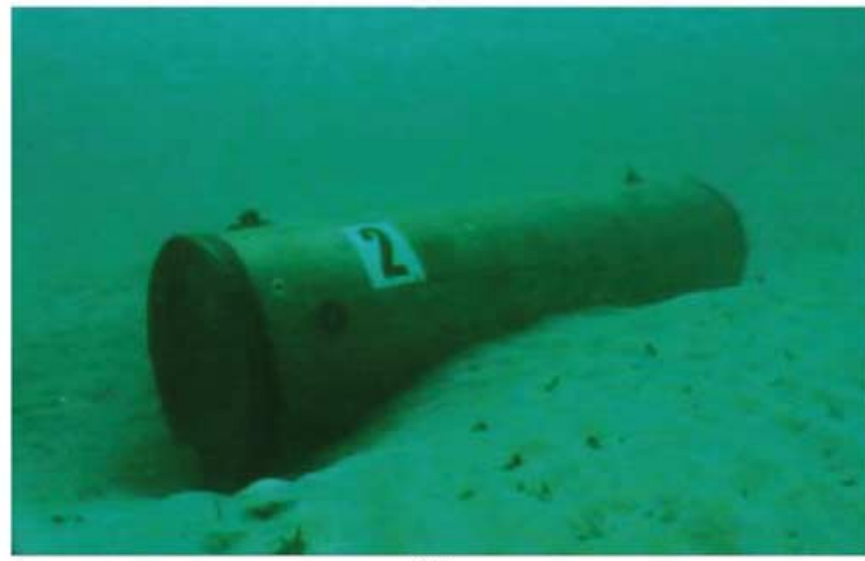

(b)

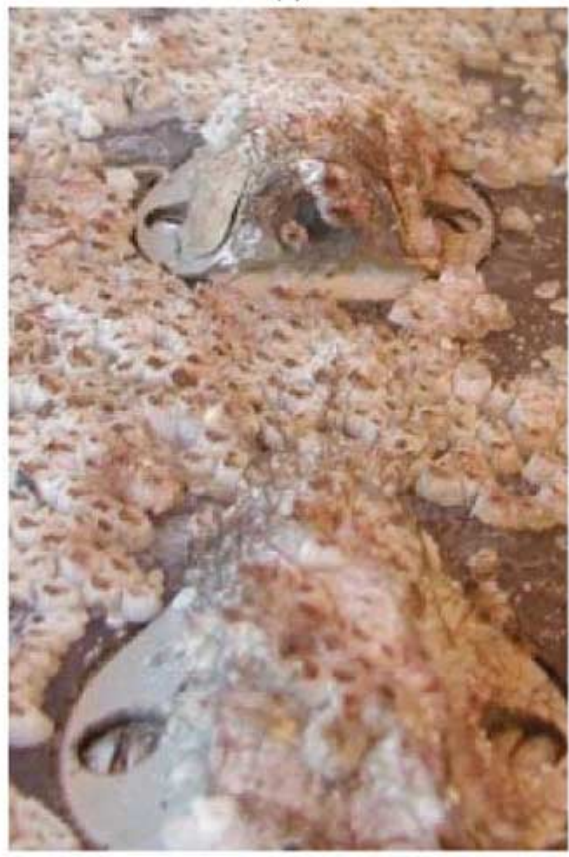

(c)

Fig. 6. (a) Optically instrumented mine being deployed on medium sandy sediment at MVCO (photograph by R. I. Ray, NRL). The 5-cm-path-length transmitter/receiver pairs are clearly visible. (b) Acoustically instrumented mine. The acoustic transducers are barely visible. (c) Close view of an optical transmitter/receiver pair at the end of the deployment B in year 1 showing biofouling by barnacles.

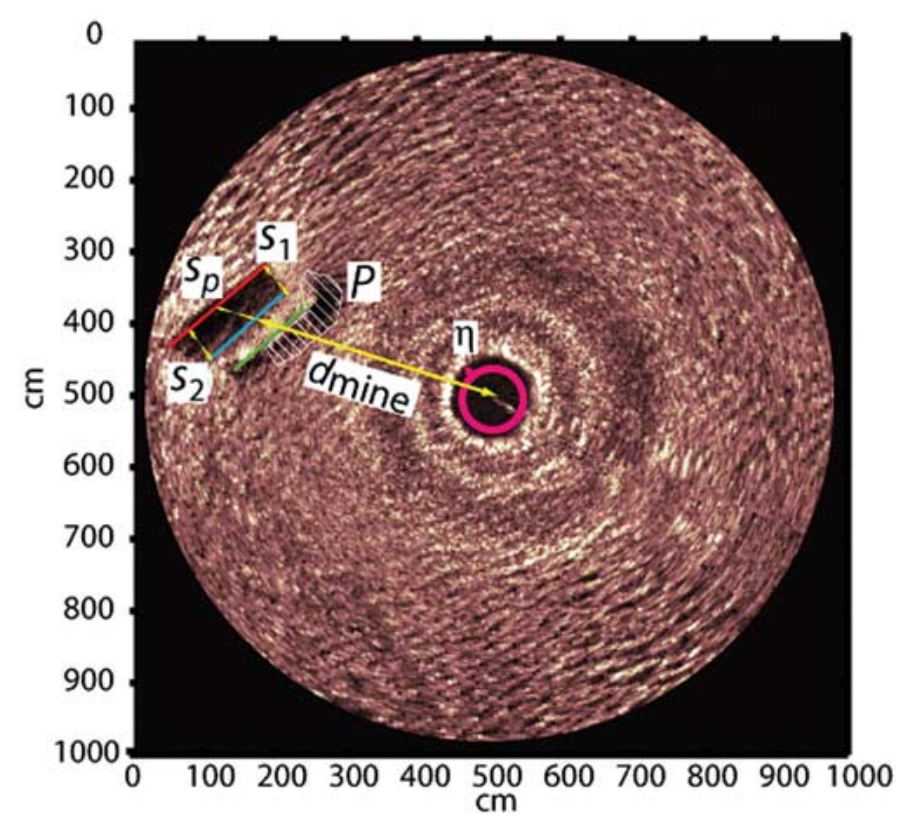

Fig. 7. Rotary sonar image from the beginning of year 1 deployment A, showing the geometric parameters estimated from the sonar images. This image is not rotated into a geographic reference frame while subsequent images are.

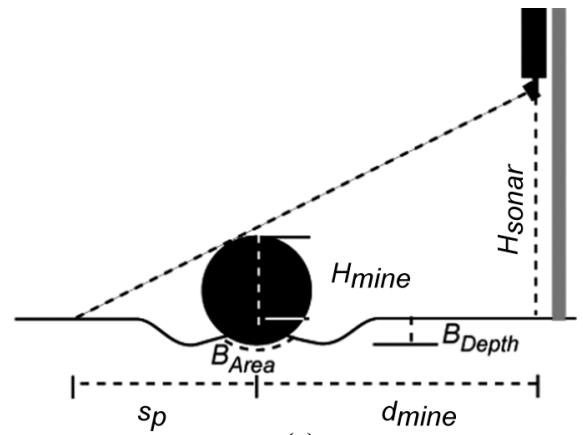

(a)

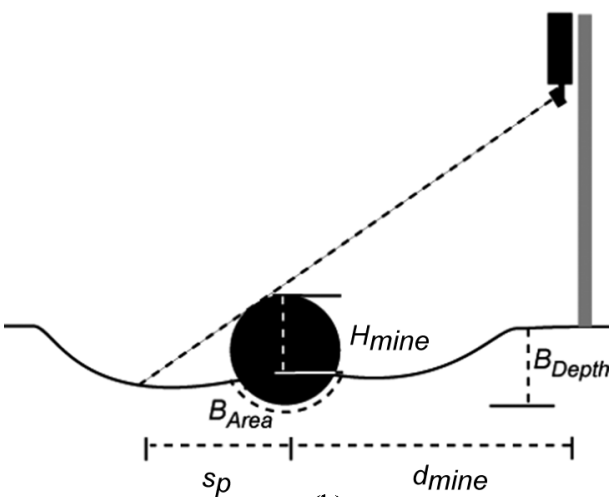

(b)

Fig. 8. Schematic diagrams showing how the mine height above the ambient seafloor can be calculated from the sidescan-projected shadow length. (a) During the initial stages of scour, the scour pit is smaller than the shadow length and the shadow length correctly estimates the depth of burial relative to the average ambient seafloor elevation $\left(B_{\text {depth }}\right)$. (b) If the scour pit is larger than the shadow length, this calculation correctly estimates the height above the local seafloor in the scour pit and the surface area burial $\left(B_{\text {area }}\right)$.

this case, there is a discrepancy in the estimate of the burial by depth relative to local seafloor in the scour pit $\left[H_{\text {mine }}\right.$ in Fig. 8(b)] and the burial by depth relative to the seafloor elevation outside of the scour pit [ $B_{\text {depth }}$ in Fig. 8(b)]. 
Surface area percent buried $\left(B_{\text {area }(\%)}\right)$ is estimated from the acoustic shadow length by

$$
B_{\text {area }(\%)}=\frac{1}{\pi} \cos ^{-1}\left(\frac{H_{\text {mine }}-r}{r}\right)
$$

where $r$ is the radius of the mine. The area of the end caps is ignored, consistent with the method of the surface area burial estimation using the optical sensors.

The scour pit length scale (the square root of the scour pit area) was made from a manual measurement of the area of reduced backscatter due to the scour pit (region $P$ in Fig. 7). The area was only measured in the quadrant nearest the sonar since the scour pit was in the shadow of the mine for the other quadrants. These manual measurements were made every tenth image ( $5 \mathrm{~h}$ apart) during periods of low bottom stress while during periods of obvious scour, measurements were made on each image. This approach avoided manually measuring more than 15000 images collected during the three years.

An estimate of bed elevation in a circle of approximately 1-m radius around the sonar-mounting pole was also produced by examining the first acoustic return from the seafloor. Unlike the latter returns, the first return occurs from the edge of the first transducer sidelobe, thus both the angle and the range to the seafloor are known, and elevation changes between subsequent images can be estimated. To estimate the bed elevation changes, the distance [parameter $\eta$ in Fig. 7(a)] between this first return and reference circle (magenta circle in Fig. 7) is averaged about the $360^{\circ}$ revolution of the sonar and multiplied by $\cos \left(60^{\circ}\right)$ to account for the sidelobe geometry [12]. The bed elevation estimate did not require manual measurement, as a threshold detector on the range gradient of the backscattered intensity was able to quantify where the first sidelobe of the sonar intersected the seafloor. This operation was performed on every image to estimate changes in bed elevation near the sonar.

The backscattered intensity before the acoustic energy scatters from the seafloor can also be used as a qualitative proxy for the amount of suspended sediment. During high-energy wave events with high concentration of suspended sediment, the dark hole in the center in the sidescan imagery becomes brighter with scattering from suspended particles.

2) Rotary Pencil-Beam Sonars: The rotary sidescan sonar produces an image of the scour pit based on acoustic intensity from seafloor slope relative to the transducer head, but does not give a quantitative elevation measurement of the scour pit and mine surface. During the third year, an Imagenex pencil-beam sonar with two stepper motors was deployed to image mine burial in fine sand. The two stepper motors allow rotation about both the vertical (azimuth drive) and horizontal (polar drive) axes; thus, the sonar can image a complete hemisphere below the transducer. The pencil-beam returned signal was sampled with 512 points in a $5-\mathrm{m}$ maximum range. This, combined with a $10-\mu$ s pulse length, yields an approximately $1-\mathrm{cm}$ range resolution at high grazing angles. This system had an adjustable center frequency that was set to $975 \mathrm{kHz}$. The horizontal resolution of the system is determined by both the beam pattern of the transducer and the step size chosen for the stepper motors. The beamwidth of the transducer was $1.4^{\circ}$, which at ranges of
$1.5-3 \mathrm{~m}$ gives a horizontal resolution on the seafloor of $7-15 \mathrm{~cm}$, respectively. The stepper motors were set to $3^{\circ}$ steps in azimuth and $1.2^{\circ}$ steps in polar angles. Due to the geometry of this system, the horizontal resolution is highest directly under the sonar and decreases with distance; a nominal horizontal resolution at the 2-3-m distance, where the mine was located, is $10 \mathrm{~cm}$. The backscatter data has been scaled with a range correction to compensate for spherical spreading and attenuation with the instrument's time variable gain. No correction to the backscatter was made for the angle of incidence relative to the local topography (e.g., Lambertian correction). From examining the data, it was found that at horizontal ranges greater than $4 \mathrm{~m}$ the bottom return was poorly detected, presumably due to the low grazing angles, thus the final bathymetric images were limited to horizontal ranges less than $4 \mathrm{~m}$.

A bathymetric surface was mapped from the data by using a threshold detector on the leading edge of the returned pulse to determine the range from the transducer to the seafloor in each ping. This was performed in postprocessing as the system returned the entire 512-point range profile of backscattered pressure for each ping. With a known range, azimuth and polar angle, a surface was mapped and interpolated onto an even 2-D grid using a MATLAB 2-D interpolation routine. There is uncorrected distortion of the calculated bathymetric surface at low grazing angles due to the beam spreading and the use of a leading edge threshold detector. This leads to horizontal and vertical distortion of less than $5 \mathrm{~cm}$ with a mine located $1.5 \mathrm{~m}$ of the horizontal distance from the sonar. This distortion increases linearly with horizontal range from the sonar [23].

The two-axis rotary pencil-beam sonar takes longer to image the mine than the rotary sidescan, (15 min versus $30 \mathrm{~s}$ per unaveraged image) as the pencil-beam system must step through $180^{\circ}$ on each axis of rotation. The pencil beam also images a smaller region than the sidescan for a given frequency due to more severe grazing angle constraints. However, the pencilbeam system produces a quantitative bathymetric measurement of the scour pit and the mine's position in the scour pit, which can be more useful for quantifying the dimensions of the scour pit than the sidescan imagery. The pencil-beam system also has the advantage of measuring the elevation of a point on the seafloor and the backscattered intensity from that point independently, while with the sidescan sonar the elevation is inferred from the intensity.

Acoustic backscatter can be useful in inferring the grain composition of the scoured or infilled surface, since coarse-grained surfaces appear to have higher backscatter strengths at MVCO. In the medium to coarse-sand regions of the RSDs, this trend was confirmed by comparing sediment grain size from grab samples with $100-\mathrm{kHz}$ sidescan backscatter imagery (see [9] and Figs. 2 and 4). Recent work on seafloor scattering at megahertz frequencies has shown that the spectra of backscatter strength versus $k a$ (where $k$ is acoustic wave number and $a$ is particle radius) peaks at approximately $k a=0.7$ as a result of scattering from grain-dominated microroughness [25]. In our $975-\mathrm{kHz}$ data, the peak in backscatter strength ( $k a=0.7)$ should occur with $350-\mu \mathrm{m}$-diameter grains. Thus, winnowing the smaller fine sand, silt and clay particles from the infilled material in the scour pit during erosion should 
result in higher backscatter. In the absence of bubbles or other volume heterogeneity, high-porosity silts and clays typically have lower backscatter strengths than sand [26]. Since the backscatter measurements are taken as the fine sediment is deposited in the scour pit, we expect this sediment to have low acoustic backscattering strength due to its high porosity, relative homogeneity, and absence of bubbles. While measurements of porosity were not taken as the sediment was deposited, measurements of fine sediment deposition in other studies usually show it has high porosity and is relatively homogenous [27], [28].

\section{Mine Deployments}

During year 1 deployment, the Imagenex rotary sidescan sonar was installed near an optically instrumented mine deployed in fine sand approximately $30 \mathrm{~m}$ south of the MVCO node. Images were collected every 30 min between December 5, 2001 and April 5, 2002, except for days between January 22 and February 8, 2002, when the MVCO developed a ground fault. The optically instrumented mine and rotary sonar were redeployed near the same location on April 5, 2002 and data was collected until July 31, 2003. Both the optical mine and the sonar produced a good data set during both year 1 deployments. A Simrad rotary sonar was also deployed in coarse sand without a mine during this period to image the evolution of naturally occurring large wavelength ripples.

During year 2, the same optically instrumented mine was deployed on December 19, 2002 in coarse sand approximately $100 \mathrm{~m}$ to the east of the MVCO node and recovered on April 24, 2003. The optically instrumented mine produced a usable data set, although there were some issues with biofouling (Fig. 6). During this deployment, the rotary sidescan sonar failed on installation due to cabling problems, thus no sonar imagery is available.

During year 3 main deployment, ten cylindrical instrumented mines (four AIMs and six optical mines) and six passive noninstrumented mines of varying geometries were deployed in both the fine and coarse sand at MVCO on September 29 and October 1, 2003 (Fig. 1). The mines were deployed in three groups to characterize scour burial processes in both the coarse and fine sand. Mines were placed on grids with approximately 25-m spacing between mines to prevent mines from influencing each other. On December 5, 2003, the four AIMs were removed from their scour pits and repositioned on sediment surface within 3-4 $\mathrm{m}$ of their original positions (Fig. 1). During April 16-18, 2004, most of the mines were recovered; however, some of the more deeply buried mines in fine sand could not be located because of poor visibility and otherwise difficult diving conditions. All but one of the instrumented mines were recovered during summer 2004. High-resolution multibeam bathymetric surveys, capable of resolving mines at the seafloor, were conducted as follows: 1) immediately following the initial deployment, 2) before the repositioning, and 3) before the final recovery [8]. The two AIMs that were deployed in fine sand, $20 \mathrm{~m}$ to south and east of the MVCO node, were cabled to the node for power and real-time data retrieval. An Imagenex rotary sidescan sonar and a two-axis pencil-beam sonar were also deployed near one of these AIMs in fine sand. The two other AIMs were deployed in coarse sand $100 \mathrm{~m}$ east of the node. These mines were not cabled to the node; however, a Simrad rotary sonar was deployed with a 100-m cable to the node near one of the AIMs in coarse sand.

Of the six optically instrumented cylindrical mines, one was deployed in coarse sand $25 \mathrm{~m}$ from the AIMs, three were deployed $300 \mathrm{~m}$ to the west of the MVCO node, and two were deployed $60 \mathrm{~m}$ south of the node. This choice of location was motivated by predeployment coring surveys, which revealed that the fine-sand layer near the node was relatively thin (approximately $20-30 \mathrm{~cm}$ ). Therefore, a second group of six mines was deployed in a region with a thicker layer $(40-50 \mathrm{~cm})$ of fine sand to the west of the node, where deeper burial might be expected. All mines in both year 3 main deployment and previous deployments were placed at approximately the same water depth of 11-12 m.

\section{RESULTS}

\section{A. Diver Observations and Oceanographic Forcing}

Since all the mines required dive operations to attach a lift line for recovery, divers used these opportunities to measure the final state of the mine orientation and burial and to observe sediment characteristics near the mine. While these observations and measurements do not reveal the details and timing of the burial processes, they do provide in situ information on sediment grain size and porosity that is useful to interpret the sonar imagery. The results from all the recovery dives in years $1-3$ are presented in this section to provide an overview of the final burial states relative to the wave forcing and sediment characteristics. In Section IV-B, the details of the burial processes are examined.

At the end of year 1 deployment of the optically instrumented mine in fine sand, divers reported that the mine and scour pit were completely buried with an approximately 10 -cm-thick layer of fine sand covering a mud and fine-sand-filled scour pit. The divers described the color of the infilled material as being substantially darker and having a softer texture than the fine-sand layer covering the scour pit. A grain-size distribution from a sediment sample taken from the scour pit shows a distinct sand (65\%) and clay/silt (35\%) mode (Fig. 4). Based on a grab sample survey, the fine-sand areas in the RSD field typically had clay/silt fractions of less than $3 \%$ as opposed to the $35 \%$ found in the scour pit [9]. The mean grain size of the clay/silt fraction in the scour pit sample was $3.2 \mu \mathrm{m}$, whereas the mean grain size of the sand-sized particles $(>63 \mu \mathrm{m})$ was $150 \mu \mathrm{m}$, which is consistent with grab samples collected in the fine sand away from the mine scour pit. Complete burial occurred during the first 70-day period, in which there were five energetic wave events with significant waveheights of 3-4 m [Fig. 3(a)]. The second 121-day deployment of the same optical mine in fine sand during year 1 resulted in only partial burial (the top of the mine was exposed approximately $10 \mathrm{~cm}$ above the ambient seafloor) during three wave events with significant waveheights between 2 and $3 \mathrm{~m}$.

At the end of year 2 deployment of the optically instrumented mine in coarse sand, divers reported the mine partially buried so that the top of the mine was approximately $15 \mathrm{~cm}$ above 
the crests of the $10-15-\mathrm{cm}$ height ripples. The divers also reported that the mines were aligned with the ripple crests and that there was minimal scour visible around the mines. This partial burial occurred with energetic wave conditions with several 3-4-m waveheight events, similar to year 1 winter conditions [Fig. 3(b)].

Divers reported that the two AIMs deployed in the coarse sand in year 3 were buried in a similar manner to the optical instrumented mine deployed in coarse sand in year 2 even with slightly more energetic wave events than during the previous coarse-sand deployment. At the December repositioning cruise, divers reported that approximately $10-20 \mathrm{~cm}$ of the mine was exposed, depending on the position of the ripples relative to the mine. At the time of the final recovery on April 16, 2004, the AIMs in coarse sand were still exposed by $10-15 \mathrm{~cm}$, despite several more energetic wave events. The other two optically instrumented mines and the noninstrumented mines deployed in coarse sand were also found partially buried upon recovery in April 2004. Vibracores taken near the coarse-sand site show a thin (2-3-cm-thick) gravel layer with granules of approximately $2-5 \mathrm{~mm}$ in diameter. Since this is below the depth of burial of any of the mines in coarse sand, it is not expected to have influence the burial results.

During year 3 December repositioning cruise, divers observed that the two AIMs in fine sand were located in deep scour pits with the top of the mines approximately at the same level with the ambient seafloor outside the scour pit. The scour pits had not filled completely so that approximately $50 \%$ of the surface areas of the mines were exposed. This degree of surface area burial was also observed in the high-resolution multibeam surveys [Fig. 5(d)]. By the time of the April final recovery cruise, all the instrumented and noninstrumented mines located in fine sand were completely buried. The deep scour pits associated with all the mines had filled in with mixture of sand and mud and a 5-15-cm-thick layer of fine sand had formed over the mines and scour pits, similar to year 1 fine-sand burial events.

Vibracores taken near the AIM site in fine sand revealed a transition to coarse sand at $20-30 \mathrm{~cm}$ below the seafloor, and there was occasionally a gravel layer at this transition. Evidently, this coarse-sand layer, possibly with some gravel, did not prevent complete burial of mines in fine sand because the AIMs were observed to scour $50 \mathrm{~cm}$ into the bed. The possible presence of a coarse layer may have prevented further scour beyond $50 \mathrm{~cm}$ from occurring. At the fine-sand site, further to the west, the coarse-sand transition occured deeper (approximately $40-50 \mathrm{~cm}$ ) and a gravel layer was not observed in the single core taken at this location. The optically instrumented and noninstrumented mines also buried completely at this site.

The timing of the complete infilling is relatively consistent relative to wave events for both year 1 and year 3 deployments. In both years, the complete infilling occurred after the maximum energy wave events of the winter season and during a period when the seasonal waveheight envelope was decreasing (Fig. 3). In year 3, this period of decreasing waveheight occurred at the beginning of the second deployment, and thus, the mines had not buried completely by the December 16-18 redeployment cruise [Fig. 3(c)]. In the first year 1 deployment, the recovery occurred just after the peak in the seasonal waveheight envelope and complete burial had occurred [Fig. 3(a)].

The diver and multibeam observations show a consistent picture of mines falling into deep scour pits in fine sand in the first few energetic wave events and then, eventually, these scour pits fill with sand and mud and the mines are completely buried. The timing of the infilling appears to be dependent on the seasonal wave climate. In contrast, mines in coarse sand bury partially in response to the first few energetic wave events, and then, they remain in the same partially buried state with subsequent wave events. However, these widely spaced temporal observations of mine burial do not reveal the exact timing of the burial relative to the forcing, and only give some indication of the burial processes. The rotary sonar observations and internally recorded burial behavior presented in Sections IV-B provide a better temporal characterization of the interactions of mine burial and forcing conditions.

\section{B. Sonar Observations of Burial Processes}

For the purposes of illustrating burial processes in fine sand, we have chosen the rotary sidescan data set from deployment $\mathrm{A}$ in year 1 and the two-axis pencil-beam data set from the deployment $\mathrm{A}$ in year 3 . These data were chosen as they show the scour and infilling processes clearly, although the other rotary sonar data sets also show a similar sequence of events. The only rotary sonar data set in coarse sand with a mine in the field of view of the sonar was recorded during deployment A of year 3 .

1) Rotary Sidescan Observations in Fine Sand: The first series of images (Fig. 9) is selected to show mine burial during the first wave event of year 1 deployment. During this wave event with maximum rms velocity of $25 \mathrm{~cm} / \mathrm{s}$, a scour pit developed around the mine and the mine fell into the scour pit over a period of a day. The sonar images show that scour is most pronounced at the ends of the mine (Fig. 9) which is consistent with data from the optical sensors on the mine. Both the sonar imagery and the in situ roll, pitch, and heading sensors show that the mine rotated $20^{\circ}$ to align the long axis of the mine to be perpendicular to the incoming wave direction Fig. 9(d). As the mine fell into its own scour pit, it rolled $5^{\circ}$ and pitch-fluctuated as one end fell in deeper than the other. Analysis of the acoustic shadow length from this event revealed the mine went from $10 \%$ buried before the wave event to $45 \%$ buried during the peak of the wave event [Figs. 9(a) and (b) and 10(b)]. The optical measurements of surface area burial show 35\% buried after this event [Fig. 10(b)]. This discrepancy is consistent with the small scour pit relative to acoustic shadow length shown in Fig. 8(b) and discussed previously.

The sonar imagery also shows anorbital wave ripple bedforms associated with the low wave orbital velocities during the initial stages of the wave event [Fig. 9(a)]. During the peak of the wave event, the ripples disappear [Fig. 9(b)] as the bed goes to a plane-bed configuration. However, some evolution of larger scale $(3-10 \mathrm{~m})$ bedforms is evident as the seafloor elevation near the sonar increases by $2 \mathrm{~cm}$ during this event [Fig. 10(c)]. The sonar imagery shows that the scour pit associated with the mine does not appear to be large enough to influence this measurement. 



Fig. 9. Sidescan sonar images during the first wave event of year 1 deployment A. The instrumented mine is located in the upper left portion of the sonar image (yellow dots are drawn on each end of the mine) and goes from the initial condition of 10\% buried at deployment (a) to approximately 35\% (optical estimates) and 45\% (acoustical shadow estimates) buried (c), as can be seen by the decrease in acoustic shadow length. The rotation of the mine towards perpendicular to the incoming waves is also seen in the sonar imagery from panels (b) and (c). The red line has length equal to the rms surface gravity wave velocity (in millimeters per second using the $x$ - and $y$-axis centimeter scale) and is parallel to the direction of wave propagation. The blue vector depicts the speed and direction of the mean currents, also in millimeters per second. The magenta ring marks where the first sidelobe of the sonar projects on to the seafloor at the beginning of the deployment. (d) Time series of significant waveheight and rms velocity with the time of the images denoted by (a)-(c). (e) Time series of heading, pitch, and roll of the mine.

The acoustic shadow length does not change significantly during the moderate-energy wave events from day 5 to day 29 [Fig. 10(a) and (b), year 1, deployment A], despite the fact that the optical sensors and the acoustic imagery show enhanced scour near the ends of the mine during these events. The lack of variability in the acoustic shadow length during this period can be explained by the mine not sinking lower into the scour pit and the scour pit not becoming large enough to affect the acoustic shadow length (Fig. 8).

During a ten-day period starting on day 32 there was a sequence of high-energy wave events that resulted in the scour pit increasing in length from 1.5 to up to $7 \mathrm{~m}$ (Fig. 10, where scour pit length is the square root of the scour pit area). On day 32-33 the mine again changes pitch, roll, and heading angle as it falls into the newly created scour pit. The elevation of the seafloor under the sonar decreases by $15 \mathrm{~cm}$ on day 32-33 [Fig. 11(n)]. Part of this elevation change could be related to scour around the mine, as the scour pit is large enough to influence the area under the sonar, as indicated by the asymmetry of the elevation under the sonar in Fig. 11(b) and (c). The heading after day 33 is almost directly perpendicular to the incoming wave direction
[Fig. 11(b) and (c)]. On day 36.6 [Fig. 11(e)], as the wave energy decreases and during slack tide, a large area of uniformly low backscatter appears in the scour pit. Previously [Fig. 11(c)], the scour pit had high backscatter from the far-side of the pit that is angled towards the sonar and low backscatter on the nearside of the pit, which is angled away from the sonar. The area of uniform backscatter does not display this type angular dependence. Based on the divers observation that the scour pit was filled with mud and the correlation between grain size and scattering strength, this area of uniform low backscatter is interpreted as mud infilling of the scour pit. As tidal velocities increase $5 \mathrm{~h}$ later [Fig. 11(h)] with continued low-energy waves, the mud is washed out of the scour pit as indicated by the return of high, angularly dependent scattering strengths. During the next slack tide, the mud infills the scour pit again [Fig. 11(i)].

Before and during the period of mud infilling, the bed elevation under the sonar gradually rose $15 \mathrm{~cm}$ relative to the sonar [days 33-39, Fig. 11(n)]. The early portion (days 33-36) of this elevation increase, before the mud infilling, is due to infilling with fine sand as indicated by the relatively high backscatter levels. As the wave energy increases on day 39, the scour pit 

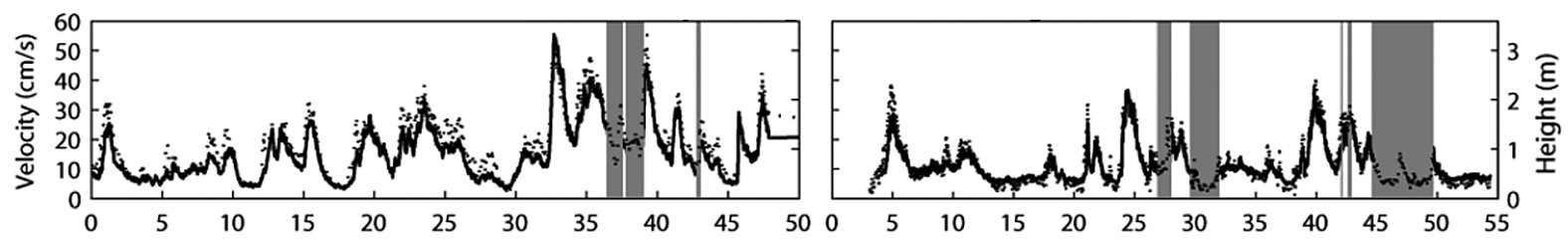

(a)


(b)


(c)
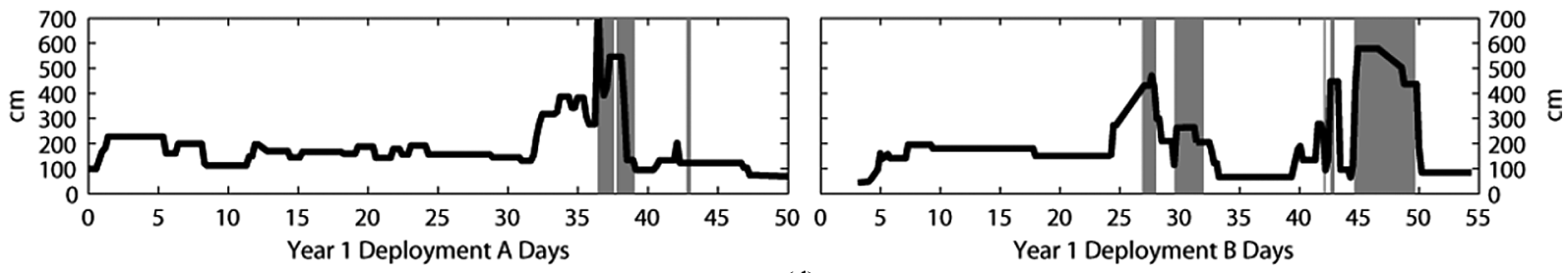

(d)

Fig. 10. Time series of parameters derived from the sonar images for the first deployment (year 1, deployment A on the left and deployment B on the right) in fine sand along with wave statistics and percent burial from the optical sensors. The gray-shaded regions indicate periods when fine sediment had infilled the scour pit. The dotted lines in panel (b) are surface area burial measurements from the optical sensors, and the solid line is the burial estimate from the rotary sidescan acoustic shadow length. (a) Wave velocity and significant waveheight. (b) Rotary sonar and optical estimates of surface area percent burial. (c) Rotary sonar bed elevation estimates. (d) Scour pit length estimate.

becomes covered with fine sand, with some of it in suspension as indicated by the high returns before the first bottom return [Fig. 11(j)]. Only a small area of the mine (15\%) is exposed at this stage. With continued high-energy waves on day 39 , bed elevation decreases $15 \mathrm{~cm}$ due to erosion of infilled fine sediment. Additional infilling and elevation increase under the sonar occurs until day 43 [Fig. 11(j)]. The next wave event on day 43 forms a small (1-2 m) scour pit that experiences similar mud infilling events [Fig. 11(k)]. Unfortunately, the MVCO node malfunctioned between deployment day 48 and 76, and thus, no data is available during this period. By day 76 [Fig. 11(1)], a layer of fine sand with anorbital-scale ripples has completely covered the scour pit and the mine. The presence of the mine beneath the surface does not perturb the ripple field in any visible manner. This is not unexpected as the divers observed that the fine-sand layer over the mine was approximately $10 \mathrm{~cm}$ thick and anorbital ripples in this fine sand have a height of 1 to $2 \mathrm{~cm}$.

Rotary sidescan observations during deployment $\mathrm{B}$ in year 1 of the optical mine in fine sand show similar sequence of events (Fig. 10, right side panels). In this deployment, the mine also buries $50 \%$ during the first moderate-energy wave event. After subsequent wave events, a large scour pit develops and the scour pit again infills with fine sediment as indicated by an area of reduced sidescan backscatter (Fig. 10, gray-shaded regions). The primary difference between this deployment and the previous one is the final depth of burial. The wave energy in deployment B (three events with 2-3-m waveheights) was considerably lower than the deployment A (3-4-m waveheights) (Fig. 3). Although the scour pit is approximately the same area as in the previous deployment (Fig. 10, bottom panels), it may not have scoured as deeply during the less energetic deployment B. Thus, the depth of burial of the mine may not have been deep enough to allow complete burial by infilling. An additional possibility is that the large changes in bed elevation, which occurred during the deployment A (Fig. 10), and did not occur during the deployment B, may have played an important role in allowing the complete burial of the mine by infilling. These elevation changes may reflect changes in the medium scale bedforms as observed by the multibeam bathymetry surveys (Fig. 5). Since these elevation change measurements were made $3 \mathrm{~m}$ from the mine, they are not completely independent of the mine scour pit.

During the deployment of the AIM in fine sand (year 3 deployment B) with the rotary pencil-beam sonar mounted nearby, an opportunity to examine the role of medium scale bedforms in mine burial existed as a suite of instruments was deployed on a four legged frame (quadpod) approximately $60 \mathrm{~m}$ from the node in fine sand (Fig. 1), with no mine near the instruments. While the a two-axis pencil-beam sonar on the quadpod 



Fig. 11. (a)-(d) Sidescan sonar images during a period of high-energy waves in year 1, deployment A. A large scour pit develops between January 7 and 8 during the $60-\mathrm{cm} / \mathrm{s} \mathrm{rms}$ wave velocities. (e) This scour pit begins to fill with fine sediment on January 11 . (f) Fine sediments are washed out of the scour pit January 11 at 18:30:00Z as the current (blue arrow) picks up. (g)-(i) Process of infilling with fine sediment and then removal of fine sediment repeats itself over the next several high wave and current periods. (j) By January 14, the mine has been completely buried except for a small corner, which is exposed and then buried over the next few weeks. (1) By February 20, the mine is completely buried and no trace of it is visible in the bedform field. 
measured $10-15-\mathrm{cm}$ elevation changes on the wave event time scale, similar to the elevation changes observed under the rotary sidescan sonar in year 1 deployment $\mathrm{A}$, these elevation changes may have been related to scour around the footpads of the quadpod. Scour pits formed around the footpads of the quadpod with a similar ratio of scour pit size to object size as the scour pits associated with the instrumented mines during energetic conditions. They both have a ratio of approximately 3 with 1-m scour pits due to $30-\mathrm{cm}$ footpads compared to $6-\mathrm{m}$ scour pits associated with a $2-\mathrm{m}$ mine. The two-axis pencil beam on the quadpod was $1.5 \mathrm{~m}$ away from the closest footpad, thus this measurement was five times the object size away from the footpad as opposed to the 2-m separation of the rotary sonar from the 2-m-length AIM. Thus, the elevation changes observed on the quadpod are a better indication that migration of the medium scale bedforms could play a role in burial, yet the elevation changes are still not completely independent of scour processes. Mud infilling of the footpad scour pits was also observed at the same time as mud infilling occurred with the instrumented mines indicating that this is a ubiquitous phenomena associated with the infilling of scour pits at this site.

2) Rotary Two-Axis Pencil-Beam Observations in Fine Sand: The two-axis sonar system used in year 3 deployments provides additional insights into the grain-size dependence of the scour and infilling processes in fine sand. The system was mounted on a 2 -in-diameter pole water-jetted approximately $2 \mathrm{~m}$ into the seafloor. This mounting technique provides minimal disturbance to the seafloor, and was adequate to support the lowprofile rotary sidescan sonar system. However, with the extra weight and hydrodynamic drag caused by the two-axis pencilbeam sonar, the pole tilted during the first few wave events and, eventually, fell over. Therefore, a single scour-infilling event where the instrument did not tilt is examined.

At the beginning of the wave event on October 21-23, 2003 [Fig. 12(a)], the mine was surrounded by a 4-m-diameter scour pit with a maximum depth of $30 \mathrm{~cm}$ below the ambient seafloor level. The mine had previously fallen into this scour pit so that the top of the mine was $5-10 \mathrm{~cm}$ above the ambient seafloor on one end. This decrease in elevation of the mine measured by the sonar was consistent with the changes in pressure difference between the AIM and the MVCO node. The backscattered intensity is relatively high on the seafloor surrounding the scour pit, but is low in the scour pit. The backscattered intensity is low on both the side of the scour pit angled toward the sonar and the side of the scour pit angled away from the sonar. Thus, the angular dependence with respect to the scattering surface is much weaker than the dependence on location (i.e., inside or outside the scour pit). Consistent with the rotary sidescan sonar observations of fine sediment infilling, we postulate that this difference in backscatter is due to the scour pit having previously infilled with finer sediment than the surrounding seafloor, and that the finer sediment has lower backscatter strength. At the peak of the wave event, with $3-\mathrm{m}$ waveheight and $40-\mathrm{cm} / \mathrm{s} \mathrm{rms}$ wave orbital velocities [Fig. 12(b)], the depth of the scour pit increased to 40-50 cm deep relative to the ambient seafloor while maintaining approximately the same diameter [Fig. 12(b)]. The ambient seafloor elevation increased slightly so the top of the mine was approximately at the same level with or a few cen- timeters above the ambient seafloor. The change in backscatter strengths in the scour pit dramatically increased compared to before the wave event [Fig. 12(a) versus (b)]. During the peak of the wave event, the backscatter is high both in the scour pit and on the surrounding seafloor. A likely explanation for this change in backscatter is that the infilled fine sediment was removed in the scour process and that coarser, higher backscatter, sediment remains. Vibracores taken near this location show a transition from fine to coarse sand at $20-30 \mathrm{~cm}$ below the seafloor, thus it is possible that some of this coarse sand contributes to the higher backscatter. As the wave event subsides, during periods of low tidal velocities, the scour pit becomes infilled [Fig. 12(c)] so that it is $10-30 \mathrm{~cm}$ deep relative to the ambient seafloor. The infilled material has lower backscatter and is occasionally almost acoustically transparent, thus there is a high variance in the bottom location estimate, as the threshold detector does not perform well with the low and variable backscatter surface. After the end of the wave event, and after several days of $30-\mathrm{cm} / \mathrm{s}$ tidal velocities, the fine-grained sediment that has infilled the scour pit has been eroded near the ends of the mine and only two lobes of fine sediment remain near the middle of the mine [Fig. 12(d)]. This is evident from the low backscatter near the middle of the mine and high backscatter near the ends of the mine. This process repeats itself in subsequent wave events with slightly more infilled material preserved after each wave event.

3) Rotary Sidescan Observations in Coarse Sand: Sonarimagery of an AIM in coarse sand deployed during year 3 shows partial burial consistent with diver observations and in situ measurements from both the AIM and an FWG optically instrumented mine deployed nearby. During the first wave event of this deployment, the AIM rotated so that it was aligned perpendicular to the dominant wave direction, and parallel to the large orbital-scale ripple crests [Fig. 13(a) and (b)]. During this wave event, the ripples have wavelengths of approximately $1 \mathrm{~m}$, heights of approximately $15 \mathrm{~cm}$, and are aligned perpendicular to the wave direction. In contrast to the fine-sand observations, a large well-defined scour pit was never visible around the mine in the coarse-sand rotary sidescan images [Fig. 13(f)]. In coarse sand, an area of small scale irregular roughness, accentuated at times by the bifurcation of the ripples [e.g., Fig. 13(c)], was observed near the corners of the mines. Once the mine has rotated to be approximately parallel with the bedforms and become partially buried, it is difficult to distinguish the mine and its shadow from the bedforms. The geometry of the acoustic return from the upper portion of the exposed mine is similar to the geometry of the acoustic return from a bedform crest, and the shadow geometry cast from the mine is similar to the shadow geometry cast by a bedform.

Analysis of the shadow length from the rotary sonar shows that the mine went from $20 \%$ buried to approximately $50 \%$ buried in the first wave event [Fig. 13(e)]. Subsequent wave events change the percent burial by $\pm 10 \%$ consistent with orbital-scale ripple migration past the mine, as observed in the rotary sonar imagery. These orbital-scale wave ripples were observed to migrate at rates of approximately one wavelength per day during the deployment of the rotary sonar in coarse sand in year 1 consistent with ripple migration observations with similar sand grain sizes [11], [12]. The pressure difference between the AIM and the MVCO node also shows the mine decreases 
(a)
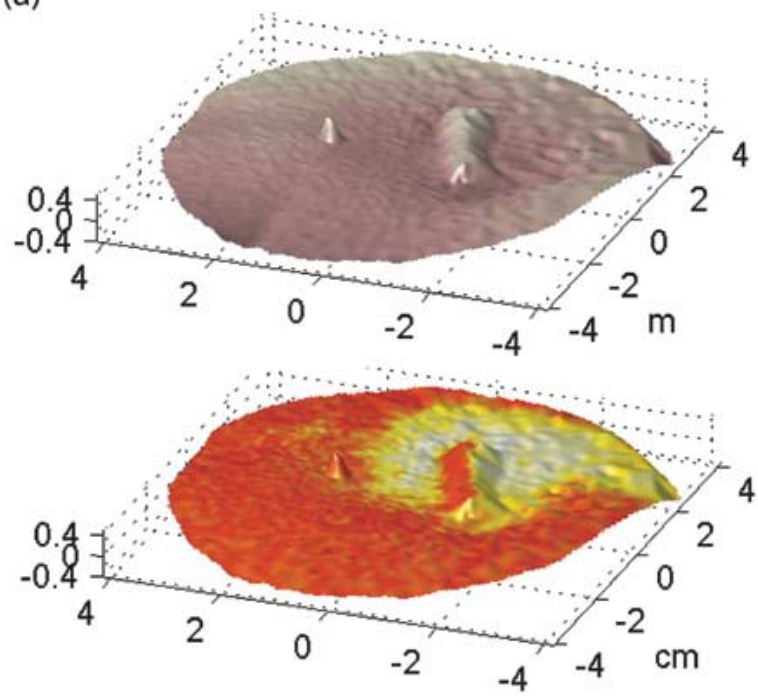

(c)
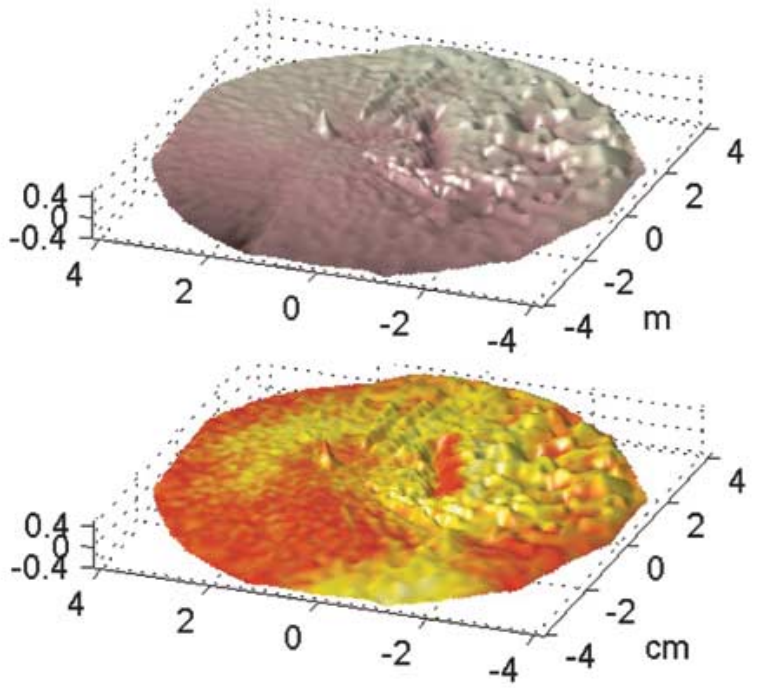

(b)

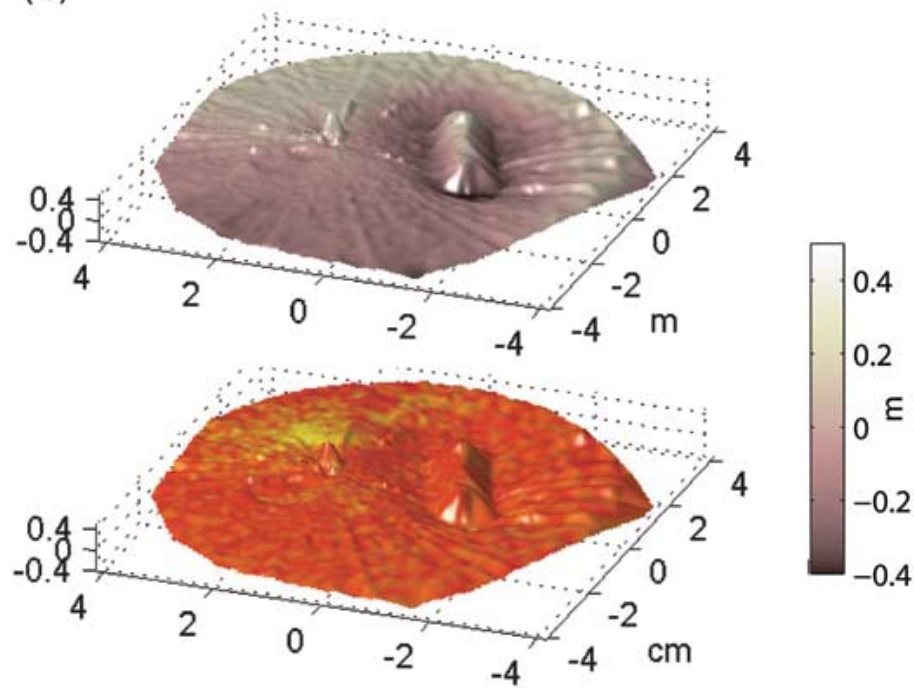

(d)

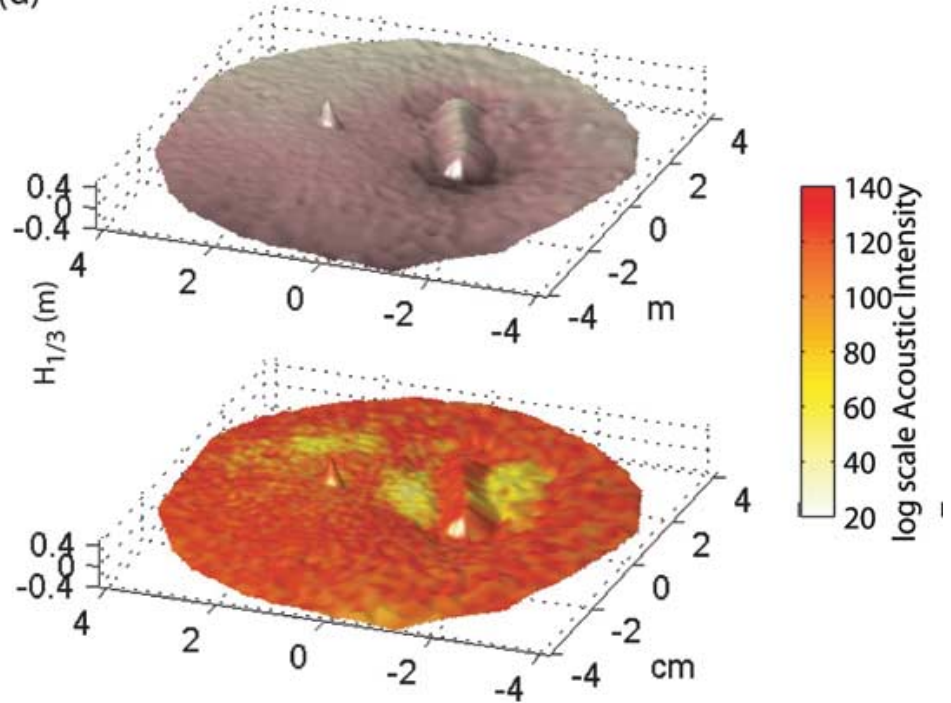

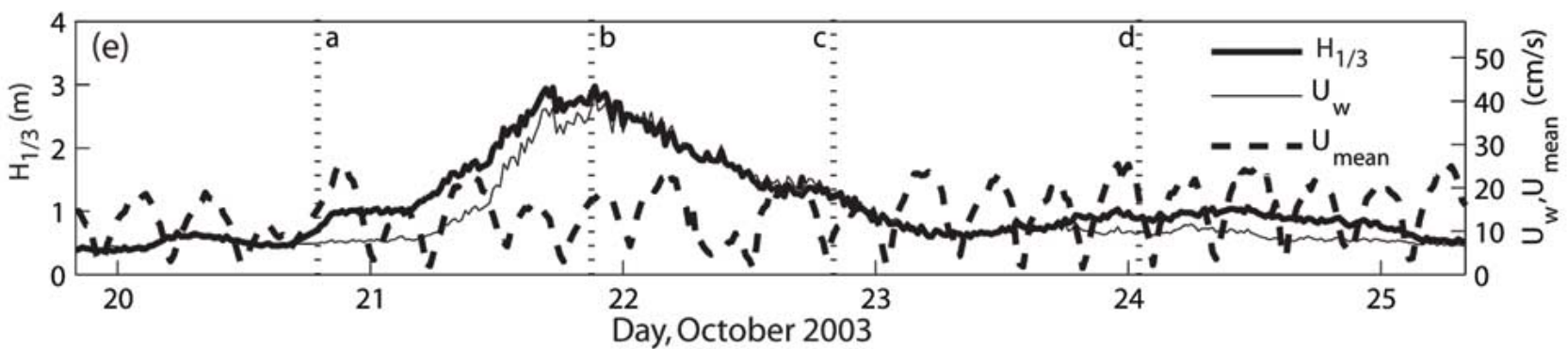

Fig. 12. Four two-axis rotary pencil-beam data sets taken at (a) the beginning, (b) peak, (c) one day following the peak, and (d) two days after a wave event. The upper image in each panel with pink hues shows the small scale bathymetry associated with the mine and its scour pit. Darker pink is bathymetrically depressed relative to a mean reference surface. The lower image in each panel with red and yellow colors shows backscattered intensity draped over the bathymetric surface. The color represents backscattered intensity with red as higher intensity. As the wave event progresses, the development and infilling of the scour pit can be clearly seen in the bathymetry data. The backscatter images reveal that surfaces exposed by scour have relatively high backscatter and infilled surfaces have much lower backscatter.

in elevation relative to the fix node during the first wave event, and then, remained at a relatively constant elevation. The physically unrealistic fluctuation (AIM decreases and then increases in elevation) around day 15 should be ignored, as it is an artifact of the filtering routine used to process the data [21]. Data from the acoustic burial transducers on the AIM also shows a significant increase in surface area burial during the first wave event [Fig. 13(e)]. The agreement between the pressure and the shadow length estimates of burial indicate burial was not due to a large scale seafloor elevation change. The rotary sonar eleva- 

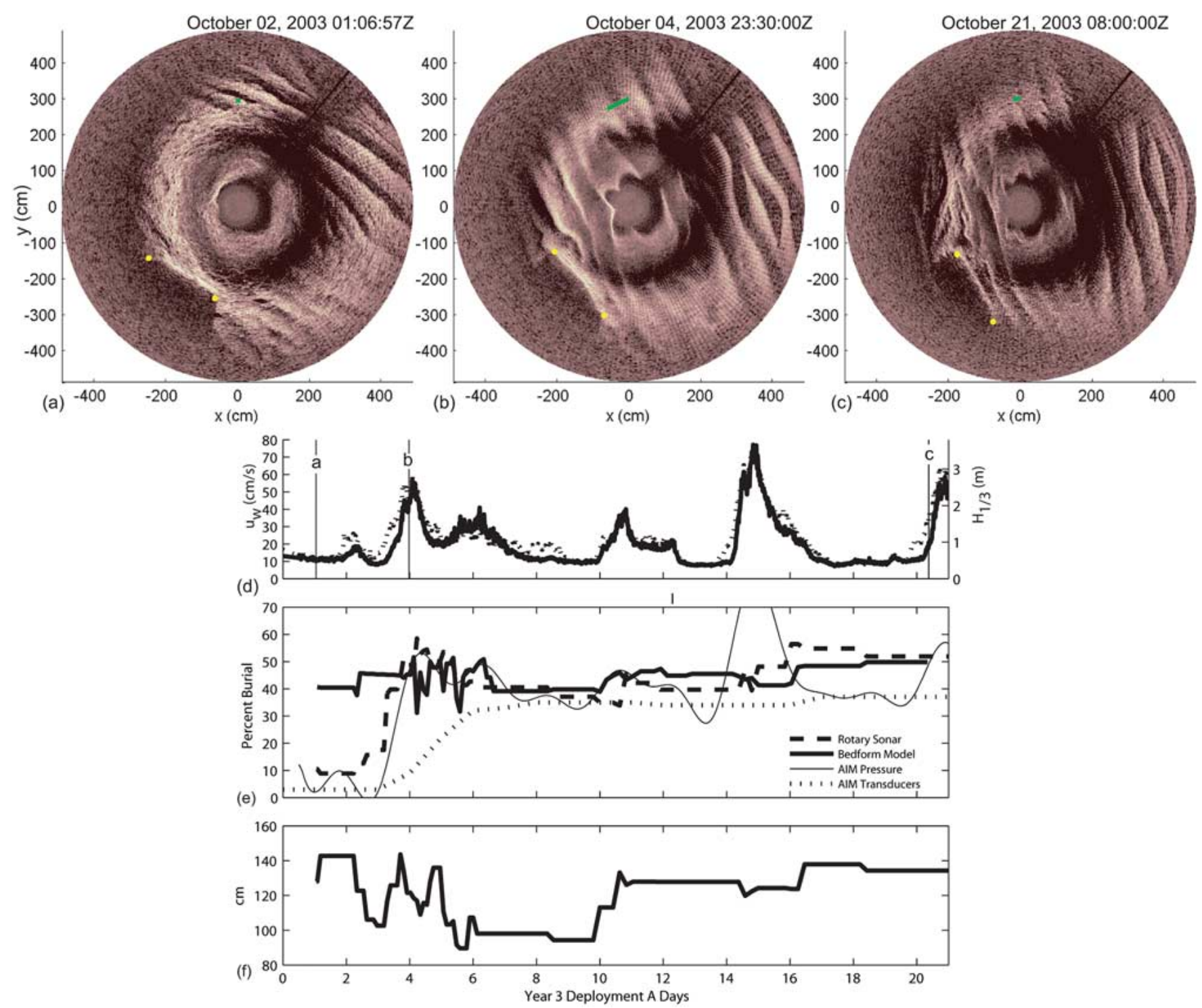

Fig. 13. (a)-(c) Three rotary sidescan images of an AIM in coarse sand. Here, the green lines superimposed on the rotary sidescan imagery have length equal to 0.75 times the wave orbital diameter and are parallel to the direction of wave propagation. The mine is visible in the lower left of the sonar image. (a) At the beginning of the deployment, it is fully exposed as indicated by the long acoustic shadow. (b) During the peak of the first wave event, the mine rotates to align parallel to the ripples, which are also parallel to the crests of the incoming waves. (c) After three wave events, the mine is partially buried so that its shadow is approximately the same length as the shadow of the large ripples. (d) The rms wave (solid line) and waveheight (dotted line) velocities. (e) Estimates of burial shown. (f) Scour pit length estimate.

tion estimate also does not show a large scale elevation change at the time of burial. Thus, the initial burial to $50 \%$ buried was probably due to localized scour near the mine, as a large scour pit was not observed.

To further examine the role of wave orbital ripple migration in controlling the $\pm 10 \%$ variance of burial after the initial burial event, a ripple migration/mine burial model was used. The model fits a sinusoidal surface to the ripple field using the wavelength, direction, and phase of the ripples in a portion of the sonar image that is several meters away from the mine. The area of the mine that is below this surface is calculated assuming the mine is initially $50 \%$ buried and does not change elevation. Consistent with the burial measurements, the predictions of this model show $\pm 10 \%$ variance during periods of high-energy waves which forces ripple migration Fig. 13(e).
Based on these observations, we postulate that in the coarse sand the mines bury until they present roughly the same hydrodynamic roughness as nearby orbital-scale bedforms, heights of $10-15 \mathrm{~cm}$ in this case. Here, the $53-\mathrm{cm}$-diameter mine buried so that at the crest of the ripple approximately $20 \mathrm{~cm}$ of the mine was exposed $\left(1.33 \eta_{r}\right)$ and in the trough of the ripple, approximately $30 \mathrm{~cm}$ was exposed $\left(2 \eta_{r}\right)$. At this stage, mines may not produce significantly more turbulence than the bedforms themselves and ripples simply migrate past the mines, producing variability about the initial burial. The significant bedload associated with ripple migration is able to fill the scour pit at a rate equal to removal by scour. This, combined with the low scour rates, since the turbulence may not be any higher around a partially buried mine than that caused by $10-20-\mathrm{cm}$-high ripples away from the mine, results 
in a maximum mine burial of near $50 \%-60 \%$ in coarse sand with orbital ripples.

\section{CONCLUSION}

Based on 14 deployments of cylindrical mines in fine sand and six deployments in coarse sand and the accompanying rotary sonar deployments over three separate years at MVCO, scour burial of mines can be summarized as follows. In fine sand, small scour pits form relatively quickly during the first energetic wave event. These scour pits allow the mines to sink so that $40 \%-80 \%$ of the mine is buried. Subsequent energetic wave conditions form a larger scour pit that allows the mine to sink until the top of the mine is approximately on the same level with or slightly below the ambient seafloor. Infilling with mud then occurs with periods of complete infill and periods of partial exposure, until the infilled sediment becomes resistant enough to resuspension so that a layer of fine sand can cover the scour pit and mine. This layer of fine sand was observed to be up to $10-15 \mathrm{~cm}$ thick and there can be no visible evidence of the mine from the surface. Medium scale ( $3-10 \mathrm{~m}$ ) bedform changes may play a role in formation of the fine-sand layers of the scour pit. However, this observational program did not obtain measurements of the migration of these features that were completely independent of scour processes during wave events, thus this would be a possibility for future work. The mud infilling process appears to have a seasonal dependence as complete burial in fine sand occurred after the seasonal peak in wave energy in both years 1 and 3 .

In coarse sand, where bedload is the dominant sediment transport mode, and large wave orbital ripples are present, mines typically do not bury completely. The mines bury until they present roughly the same hydrodynamic roughness as the orbital-scale bedforms present in coarse sand $(10-15 \mathrm{~cm})$. At this stage, we speculate that the mines do not produce more turbulence than the bedform themselves and ripples simply migrate past the mines leaving them partially buried. This could be tested with a high-resolution 3-D numerical model such as those used by Foster et al. [29], or in controlled laboratory environment [30], [31]. A field test of this conceptual model would involve measuring near-bed turbulence levels above wave orbital-scale bedforms with and without a mine present.

These results on scour pit infilling in fine-sand environments and partial burial in coarse-sand environments have important implications for prediction of mine burial, as previous scour models used to predict mine burial have not included these effects [32]. In particular, the observations show that fine sediment infilling has a dramatic effect on the final state of burial. While this paper clearly shows this mechanism exists, and reveals the timing relative to wave events, these observations do not reveal the source of the fine sediment and offers little predictive ability on whether infilling will occur in different environments. Future work in a variety of sedimentary environments with varying proximity to sources of fine sediment could potentially address this issue.

\section{ACKNOWLEDGMENT}

The authors would thank the ONR program managers who made this experiment possible: R. H. Wilkens, D. Lavoie, and
T. Drake. They would also like to thank Captain D. Nelson and crew of the R/V Connecticut for providing excellent seamanship for deployment of the equipment; J. Fredricks and M. McElroy for managing MVCO; the WHOI divers J. Sisson, G. McDonald, A. Girard, F. Thwaites, P. Schultz, and E. Horgan and the NRL divers R. Ray, R. Fisher, C. Vaughn, and K. Briggs, who worked under difficult conditions to deploy and recover equipment; R. Singer, who programmed the sonar data loggers; D. Foster of the University of Ohio for providing the use of her two-axis pencil-beam sonar; and B. Schwab of the USGS Woods Hole for collection of the sidescan sonar survey data set.

\section{REFERENCES}

[1] T. C. Austin, J. B. Edson, W. R. McGillis, C. von Alt, M. J. Purcell, R. Petitt, M. K. McElroy, J. Ware, and R. Stokey, "The Martha's vineyard coastal observatory: A long term facility for monitoring air-sea processes," in Proc. MTS/IEEE OCEANS, Sep. 2000, pp. 1937-1941.

[2] S. I. Voropayev, F. Y. Testik, H. J. S. Fernando, and D. L. Boyer, "Burial and scour around short cylinder under progressive shoaling waves," Ocean Eng., vol. 30, pp. 1647-1667, 2003.

[3] Y. A. Catanó-Lopera and M. H. García, "Burial of short cylinders induced by scour and bedforms under waves plus currents," ASCE J. Waterway, Port, Coast., Ocean. Eng., pp. 439-449, 2005, doi: 10.1061/ 40792(173)396

[4] R. J. S. Whitehouse, Scour at Marine Structures. London, U.K.: Thomas Telford, 1998.

[5] P. C. Chu and C. W. Fan, "3D rigid body impact burial prediction model," Adv. Mech., vol. 5, pp. 43-52, 2004.

[6] M. D. Richardson and P. Traykovski, "Real-time observations of mine burial at the Martha's Vineyard Coastal Observatory," in Proc. 5th Int. Symp. Technol. Mine Problem, Monterey, CA, May 22-25, 2002. CD-ROM.

[7] P. Traykovski, M. D. Richardson, J. A. Goff, L. A. Mayer, R. Wilkens, and B. Gotowoka, "Mine burial experiments at the Martha's Vineyard Coastal Observatory," in Proc. 6th Int. Symp. Technol. Mine Problem, Monterey, CA, May 9-13, 2004, CD-ROM.

[8] L. A Mayer, R. Raymond, G. Glang, M. D. Richardson, P. Traykovski, and A. C. Trembanis, "High-resolution mapping of mines and ripples at the Martha's Vineyard Coastal Observatory," IEEE J. Ocean. Eng., vol. 32, no. 1, pp. 133-149, Jan. 2007.

[9] J. A. Goff, L. A. Mayer, P. Traykovski, I. Buynevich, R. Wilkens, R. Raymond, G. Glang, R. L. Evans, H. Olson, and C. Jenkins, "Detailed investigation of sorted bedforms, or "rippled scour depressions," within the Martha's Vineyard Coastal Observatory, Massachusetts," Continental Shelf Res., vol. 25, pp. 461-484, 2005.

[10] W. D. Grant and O. S. Madsen, "Combined wave and current interaction with a rough bottom,” J. Geophys. Res., vol. 84, pp. 1797-1808, 1979.

[11] P. Traykovski and J. A. Goff, "Observations and modeling of large and small scale bedforms at the Martha's Vineyard Coastal Observatory, Coastal Sediments '03," in Proc. 5th Int. Symp. Coast. Eng. Sci. Coast. Sediment Processes, May 2003, CD-ROM.

[12] P. Traykovski, A. E. Hay, J. D. Irish, and J. F. Lynch, "Geometry, migration, and evolution of wave orbital ripples at LEO-15," J. Geophys. Res., vol. 104, no. C1, pp. 1505-1524, 1999.

[13] A. D. Murray and E. R. Thieler, "A new hypothesis and exploratory model for the formation of large-scale inner-shelf sediment sorting and 'rippled scour depressions'," Continental Shelf Res., vol. 24, pp. 295-315, 2004.

[14] F. Engelund and J. Fredsoe, "Sediment ripples and dunes," Annu. Rev. Fluid Mech., vol. 14, pp. 13-37, 1982.

[15] D. H. Swart, "Offshore sediment transport and equilibrium beach profiles," Delft Hydr. Lab., Delft, The Netherlands, Publication No. 131, 1974.

[16] P. L. Wiberg and C. K. Harris, "Ripple geometry in wave-dominated environments," J. Geophys. Res., vol. 99, pp. 775-789, 1994.

[17] M. O. Green and K. P. Black, "Suspended-sediment reference concentration under waves: Field observations and critical analysis of two predictive models," Coast. Eng., vol. 38, pp. 115-141, 1999.

[18] M. O. Green, C. E. Vincent, and A. C. Trembanis, "Suspension of coarse and fine sand on a wave-dominated shoreface, with implications for the development of rippled scour depressions," Continental Shelf Res., vol. 24, pp. 317-335, 2004. 
[19] S. Griffin, J. Bradley, M. D. Richardson, K. B. Briggs, and P. J. Valent, "Instrumented mines for mine burial studies," Sea Technol., vol. 42, no. 11, pp. 21-27, 2001.

[20] S. Griffin, J. Bradley, and M. D. Richardson, "Improved subsequent burial instrumented mines," Sea Technol., vol. 44, no. 11, pp. 40-44, 2003.

[21] J. Bradley, S. Griffin, M. Thiele, Jr., M. Richardson, and P. D. Thorne et al., "An acoustic-instrumented mine for studying subsequent burial," IEEE J. Ocean. Eng., vol. 32, no. 1, pp. 64-77, Jan. 2007.

[22] J. D. Irish, J. F. Lynch, P. A. Traykovski, A. E. Newhall, and K. Prada, "A self-contained sector-scanning sonar for bottom roughness observations as part of sediment transport studies," J. Atmos. Ocean. Technol., vol. 16, pp. 1830-1841, 1999.

[23] B. R. Gotowoka, "Analysis of 2-axis pencil beam sonar microbathymetric measurements of mine burial at the Martha's Vineyard Coastal Observatory," M.S. Thesis, Joint Program Oceanogr./Appl. Ocean Sci. Eng., MIT/WHOI, Woods Hole, MA, 2005.

[24] A. E. Hay and D. Wilson, "Rotary sidescan images of nearshore bedform evolution during a storm," Mar. Geology, vol. 119, pp. 57-65, 1994.

[25] C. F. Greenlaw, D. V. Holliday, and D. E. McGehee, "High-frequency scattering from saturated sand sediments," J. Acoust. Soc. Amer., vol. 115, no. 6, pp. 2818-2823, 2004.

[26] D. R. Jackson and K. B. Briggs, "High-frequency bottom backscattering: Roughness versus sediment volume scattering," J. Acoust. Soc. Amer., vol. 92, pp. 962-977, 1992.

[27] P. Traykovski, W. R. Geyer, and C. K. Sommerfield, "Rapid sediment deposition and fine-scale strata-formation in the Hudson estuary," $J$. Geophys. Res., vol. 109, 2004, doi: 10.1029/2003JF000096.

[28] R. A. Wheatcroft and J. C. Borgeld, "Oceanic flood layers on the northern California margin: Large-scale distribution and small-scale physical properties," Continental Shelf Res., vol. 20, pp. 2163-2190, 2000.

[29] K. A. Hatton, D. L. Foster, P. Traykovski, and H. D. Smith, "Numerical simulations of the flow and sediment transport regimes surrounding a short cylinder," IEEE J. Ocean. Eng., vol. 32, no. 1, pp. 249-259, Jan. 2007.

[30] F. Y. Testik, S. I. Voropayev, H. J. S. Fernando, and S. Balasubramanian, "Mine burial in the shoaling zone: Scaling of laboratory results to oceanic situations," IEEE J. Ocean. Eng., vol. 32, no. 1, pp. 204-213, Jan. 2007.

[31] Y. A. Cataño-Lopera, S. T. Demir, and M. H. García, "Self-burial of short cylinders under oscillatory flows and combined waves plus currents," IEEE J. Ocean. Eng., vol. 32, no. 1, pp. 191-203, Jan. 2007.

[32] A. C. Trembanis, C. T. Friedrichs, M. D. Richardson, P. Traykovski, P. A. Howd, P. A. Elmore, and T. F. Wever, "Predicting seabed burial of cylinders by wave-induced scour: Application to the sandy inner shelf off Florida and Massachusetts," IEEE J. Ocean. Eng., vol. 32, no. 1, pp. 167-183, Jan. 2007

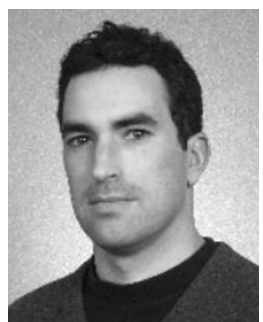

Peter Traykovski received the B.S.E. degree in mechanical engineering from Duke University, Durham, NC, in 1988 and the M.S./Engineers degree and $\mathrm{Ph} . \mathrm{D}$. degree in applied ocean sciences and engineering from the Massachusetts Institute of Technology/Woods Hole Oceanographic Institution Joint Program, Woods Hole, MA, in 1994 and 1998, respectively.

Currently, he is an Associate Scientist at the Applied Ocean Physics and Engineering Department, the Woods Hole Oceanographic Institution. His main research interests are sediment transport dynamics on the continental shelf and in estuaries and developing instrumentation to measure these processes.

Dr. Traykovski is a member of the American Geophysical Union.

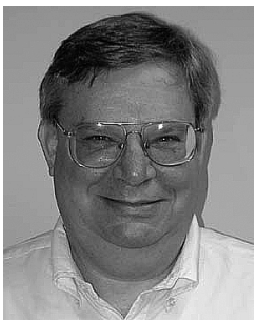

Michael D. Richardson received the B.S. degree in oceanography from the University of Washington, Seattle, in 1967, the M.S. degree in marine science from the College of Williams and Mary, Williamsburg, VA, in 1971, and the Ph.D. degree in oceanography from the Oregon State University, Corvallis, in 1976.

He began working at the U.S. Naval Ocean Research and Development Activity, now part of the U.S. Naval Research Laboratory (NRL), Stennis Space Center, MS, in 1977. Except for a five-year assignment as a Principle Scientist at NATO's SACLANTCEN, La Spezia, Italy (1985-1989), he has worked at NRL as a Research Scientist and is currently the Head of the Seafloor Sciences Branch in the Marine Geosciences Division. His research interests include the effects of biological and physical processes on sediment structure, behavior, and physical properties near the sediment-water interface in both shallow-water coastal regions and in the deep sea. His current research is linked to high-frequency acoustic scattering from and propagation within the seafloor and prediction of mine burial.

Dr. Richardson is a Fellow of the Acoustical Society of America, and a member of the American Geophysical Union, the European Geophysical Society, and Sigma Xi.



Larry A. Mayer received the B.Sc. degree in geology from the University of Rhode Island, Kingston, in 1973 and the Ph.D. degree in marine geophysics from the Scripps Institution of Oceanography, the University of California at San Diego, La Jolla, in 1979.

Currently, he is a Professor of Earth Science and Ocean Engineering at the University of New Hampshire (UNH), Durham, NH and is the Director of the Center for Coastal and Ocean Mapping and Co-Director of the National Oceanic and Atmospheric Administration (NOAA)/UNH Joint Hydrographic Center. His main research interests are in seafloor mapping technologies, seafloor characterization, and applications of advanced visualization techniques to ocean mapping problems.

Dr. Mayer is a member of the American Geophysical Union.



James D. Irish (M'05) received the B.S. degree in physics from the Antioch College, Yellow Springs, $\mathrm{OH}$, in 1967 and the M.S. and Ph.D. degrees in oceanography from the Scripps Institution of Oceanography, University of California at San Diego, La Jolla, in 1969 and 1971, respectively.

Currently, he is a Senior Research Specialist in the Applied Ocean Physics and Engineering Department, Woods Hole Oceanographic Institution, Woods Hole, MA. His main research interests are in application of new technologies and techniques for observing the ocean environment and analyzing the results to improve the understanding and use of the coastal ocean.

Dr. Irish is a member of the American Geophysical Union, the Marine Technology Society, IEEE/Ocean Engineering Society, and the Oceanography Society. 